\title{
Use of codeine-containing medicines by Irish psychiatric inpatients before and after regulatory limitations on their supply
}

\author{
V. I. O. Agyapong ${ }^{1 *}$, K. Singh ${ }^{2}$, M. Savage ${ }^{2}$,T. B. Thekiso ${ }^{2}$, M. Finn ${ }^{2}$, C. K. Farren ${ }^{1}$ and \\ D. M. McLoughlin ${ }^{1}$ \\ ${ }^{1}$ Department of Psychiatry, Trinity College Dublin, St Patrick's University Hospital, Dublin, Ireland \\ ${ }^{2}$ Department of Psychiatry, St Patrick's University Hospital, Dublin, Ireland
}

Background. In recent years, concerns have been highlighted in several jurisdictions, including Ireland, regarding abuse of over-the-counter codeine-containing medicines. On the 1st of August 2010, national regulatory guidelines aimed at limiting the supply of these medicines in Ireland came into force.

\begin{abstract}
Aims. To study the effects of the new regulations on the use of non-prescribed codeine-containing medicines by psychiatric patients admitted to an Irish university teaching hospital before $(n=117)$ the regulations came into effect and 6 months afterwards $(n=126)$.

Methods. Participants completed a brief self-administered survey questionnaire about their use of over-the-counter codeine-containing medicines in the preceding 3 months.

Results. Compared with before the introduction of the new regulations, there was a large decline in the reported 'often' or 'regular' use of codeine-containing medicines in the 3 months before admission $\left(33.3 \% v .17 .4 \%, \chi^{2}=6.354, p=0.01\right)$ and there was a reduction in the proportion of patients for whom others had expressed concerns about their frequency of use of such medications $\left(15.5 \% v .4 .8 \%, \chi^{2}=7.29, p=0.03\right)$. There was also a decline in the proportion of patients who stated that they would use codeine-containing medicines for either a 'feel-good' effect or to curb cravings $(15.9 \% v .1 .9 \%$, $p<0.01$, two-tailed Fisher's exact test).

Conclusion. We conclude that tight regulations on the supply of non-prescription codeine-containing medicines have the potential to reduce the use and abuse of such medicines in patient populations availing of admission to psychiatry hospitals.
\end{abstract}

Received 2 July 2012; Accepted 6 November 2012

Key words: Abuse, codeine, inpatients, psychiatric, regulatory guidelines.

\section{Introduction}

Codeine is a derivative of opium and is by far the most widely used opioid in the world (Hou et al. 2011). It is generally used for pain control and as an antitussive agent in cough syrups (Peters et al. 2007). Safety concerns around the misuse of non-prescription medicinal products containing codeine are well established. Though the use of opioid analgesics for the treatment of acute pain appears to be generally benign, consumption of quantities of these medicines in excess of the recommended dose, or over a prolonged period of time, may cause tolerance and dependence, as well

This paper was presented orally and as an e-poster at the 20th European Congress of Psychiatry in Prague, Czech Republic, on the 4th of March 2012.

* Address for correspondence: V. I. O. Agyapong, C/o Research Building, Department of Psychiatry, Trinity College Dublin, St Patrick's University Hospital, James's Street, Dublin 8, Ireland. (Email: israelhans@hotmail.com) as the risk of other less common adverse effects, including perforated gastric ulcers, acute pancreatitis and severe hypokalaemia complicated by myopathy (Hastier et al. 2000; Compton \& Volkow, 2006; Dutch, 2008; Frei et al. 2010; Ernest et al. 2010; Pharmaceutical Society of Ireland (PSI), 2010). In recent years, codeinecontaining cough syrups have also been reported as substances of abuse either on their own or as substitutes for conventionally abused drugs such as heroin, amphetamine and cocaine (Mattoo et al. 1997; Shek \& Lam, 2006; Yang \& Yuan, 2008; Lao et al. 2010).

The problem of abuse and addiction to codeinecontaining medicines has emerged as a major issue in the past decade and has worsened in recent years (Compton \& Volkow, 2006). In particular, there appears to be a high prevalence of abuse of codeinecontaining substances (e.g. Solpadine) among patients with mental health difficulties. In one Irish study, about $1 \%$ of all inpatients admitted to an acute psychiatric hospital were treated for 'over-the-counter' 
opiate abuse (Thekiso, 2010). Several studies conducted in India, France and Germany have also found high rates (up to $28 \%$ ) of psychiatric comorbidity, including increased rates of suicide attempts, among patients undergoing treatment for abuse of codeine-containing medicines (Krausz et al. 1996; Mattoo et al. 1997; Radat et al. 2002). It is therefore important to screen for addiction to codeine-containing substances among patients seeking psychiatric help. Studies also suggest that codeine use can sustain addiction or increase the risk of relapse in patients afflicted with addiction. Consequently, the risk of relapse must be considered when treating conditions such as pain or cough in a person recovering from addiction (Stock, 1991).

Recently, concerns have been highlighted in several jurisdictions, including Ireland, the United Kingdom and Canada, regarding abuse of codeine-containing medicinal products (PSI, 2010). This increase in the abuse of codeine-containing medicines appear to reflect, in part, changes in medication-prescribing practices, changes in drug formulations, as well as relatively easy access over the counter and also via the internet (Compton \& Volkow, 2006). In one study, 53 of the first 100 links generated from an internet search using the term 'no prescription codeine' were categorised as commercial opiate sites (Forman, 2003).

Efforts to regulate the sale and use of drugs of abuse are of long-standing significance (Spillane, 2004). Because of its potential for misuse, codeine is classified as a controlled drug in Ireland under the Misuse of Drugs Acts 1977 and 1984. As an analgesic, however, it is most often used in combination with other analgesics such as paracetamol or ibuprofen and is currently authorised in non-prescription products for pain relief. It is also available in single ingredient, nonprescription products, as a cough suppressant (PSI, 2010). The Irish Pharmacy Act 2007 and the Regulation of Retail Pharmacy Businesses Regulations 2008 require that all non-prescription codeine-containing medicines supplied through a retail pharmacy business be the subject of appropriate counselling. In addition, codeine-containing medicines and other controlled drugs should not be accessible to the public for self-selection. However, until recently, non-prescription codeinecontaining medicines were widely and cheaply available over the counter and could be purchased in moderate quantities without being explicitly approved by a pharmacist.

To address this, in May 2010 the Pharmaceutical Society of Ireland issued regulatory guidance (http:// www.thepsi.ie/Libraries/Consultations/Final_Codeine_ Guidelines.sflb.ashx) aimed at ensuring the safe supply of over-the-counter codeine-containing medicinal products and to assist pharmacists in discharging their legal and professional obligations to patients seeking advice, guidance and assistance in respect of the use of these medicinal products. The guidance, which became operational on the 1st of August 2010, requires, among other things, that codeine-containing medicinal products be supplied as 'second-line' products for pain relief and be supplied only when a pharmacist is satisfied that, in the exercise of his or her professional judgement, the supply of such a medicine is the most appropriate therapy available at the time and that such supply is in the best interest of the patient. The guidance also reinforces the legislative requirements that these products should not be accessible to the public for self-selection. Consequently, in a retail pharmacy business, non-prescription medicinal products containing codeine are now stored in an area under the direct control of the pharmacist and out of view of the general public (PSI, 2010).

To examine the impact of these new regulations, we studied the frequency of use and reasons for using non-prescription codeine-containing medicines in Irish inpatient psychiatry service users both before and after the introduction of the new regulations on the supply of codeine-containing medicines. We also explore the association use and abuse of codeine-containing substances and other addictions.

\section{Methods}

The study took place in St Patrick's University Hospital, Dublin, an acute 250-bed psychiatric teaching hospital and was approved by the hospital's Research Ethics Committee. All patients who were approached about the study were provided with written and verbal information about it and written consent was sought before participation. The guidelines on the supply of non-prescribed codeine-containing medicines came into effect on the 1st of August 2010. All admitted patients during the month of May 2010 and also February 2011 were invited to participate in the survey within 24 hours of admission. Patients were excluded if aged $<18$ years or lacked capacity to consent.

Demographic and clinical data were gathered by asking participants to complete a brief self-administered survey questionnaire about their use of over-the-counter codeine-containing medicines in the preceding 3 months. The questionnaire was developed by the research team and included multiple categorical demographic and clinical variable items such as age, sex, current relationship(s) and employment status, as well as frequency of use, reasons for use and effects after use of codeine-containing medicines during the previous 3 months. It also sought information from patients on other people's expressed views of their use of over-the counter codeine-containing medicines. We included a list of all over-the-counter codeine-containing 
medicines available in Ireland as a guide for the patients. The questionnaire was pre-tested with 10 patients not included in the study sample. It generally took 5 minutes to complete and no financial incentive was offered to respondents. For patients whose reading and writing abilities were limited, a member of the research team assisted them to complete their questionnaires.

After patients had completed the questionnaire, their admission diagnoses according to the ICD 10 were recorded by a member of the research team. Data are expressed as mean (standard deviation) and were analysed with descriptive statistics, independent sample $t$-tests and $\chi^{2}$ tests using the statistical package for the social sciences version 17 (SPSS Inc., Chicago, IL, USA).

\section{Results}

Of the 180 patients admitted in May 2010 (i.e. 3 months before the introduction of the regulatory guidance), 117 agreed to participate in the survey (response rate of $65 \%$ ). This compares with 126 of 184 patients admitted in February 2011 (i.e. 6 months after the introduction of the guidance) (response rate of $68 \%$ ). Demographic and clinical data for the two groups are summarised in Table 1. The two groups were well balanced with no significant differences between groups for age, sex, diagnosis, relationship and employment status, and types of diagnosis.

Patients were asked some questions about codeinecontaining medicines, including the frequency with which they use them and their awareness about the addictive nature of such medicines. A comparison of responses from both groups of patients is as summarised in Table 2.

The responses provided to the questions in Table 2 for all the study participants were compared for patients grouped according to whether they had any addictive diagnosis or not. There was no statistical difference in the responses based on the presence or absence of an established addictive diagnosis (i.e. $p>0.5$ for all responses).

Patients who had used a codeine-containing medicine in the 3 months preceding the survey were asked to indicate the reasons for which they had taken such medicines. We compared the responses from the two groups using the $\chi^{2}$ and Fishers exact tests as shown in Table 3.

The responses provided for the reasons for taking over-the-counter codeine-containing medicines for all the study participants were compared for patients grouped according to whether they had an addictive diagnosis or not. There was no statistical difference in the responses based on the presence or absence of an established addictive diagnosis (i.e. $p>0.5$ for all responses).

\section{Discussion}

Our study has established that compared with before the introduction of new regulations there was a large decline in reported 'often' or 'regular' use of codeine-containing

Table 1. Demographic and clinical characteristics of respondents before and after introduction of the regulatory guidelines

\begin{tabular}{|c|c|c|c|c|}
\hline $\begin{array}{l}\text { Baseline demographic/ } \\
\text { clinical characteristics }\end{array}$ & $\begin{array}{l}\text { Pre-regulation } \\
(n=117)[n(\%)]\end{array}$ & $\begin{array}{l}\text { Post-regulation } \\
(n=126)[n(\%)]\end{array}$ & $\chi^{2} / t$-test & $p$-value \\
\hline \multicolumn{5}{|l|}{ Sex } \\
\hline Male & $53(45.3)$ & $70(56.6)$ & \multirow[t]{2}{*}{2.553} & \multirow[t]{2}{*}{0.11} \\
\hline Female & $64(54.7)$ & $56(44.4)$ & & \\
\hline Age & $46.83(14.7)$ & $46.87(13.78)$ & $t=-0.024$ & 0.98 \\
\hline \multicolumn{5}{|l|}{ Relationship status } \\
\hline In a relationship & $67(57.3)$ & $65(51.6)$ & \multirow[t]{2}{*}{0.788} & \multirow[t]{2}{*}{0.44} \\
\hline Not in a relationship & $50(42.7)$ & $61(48.4)$ & & \\
\hline \multicolumn{5}{|l|}{ Employment status } \\
\hline Employed & $69(59.0)$ & $67(53.2)$ & \multirow[t]{2}{*}{0.828} & \multirow[t]{2}{*}{0.37} \\
\hline Unemployed & $48(41.0)$ & $59(46.8)$ & & \\
\hline \multicolumn{5}{|l|}{ Primary diagnosis } \\
\hline Depression & $40(34.2)$ & $52(41.3)$ & & \multirow[t]{5}{*}{0.72} \\
\hline Anxiety disorder & $16(13.7)$ & 17 (13.5) & & \\
\hline Bipolar disorder & $33(28.2)$ & $28(22.2)$ & 2.114 & \\
\hline Alcohol/substance use disorder & $15(12.8)$ & $18(14.3)$ & & \\
\hline Schizophrenia/schizoaffective disorder & $13(11.1)$ & $11(8.7)$ & & \\
\hline \multicolumn{5}{|l|}{ Primary or secondary addictive diagnosis } \\
\hline Yes & $32(27)$ & $44(35)$ & 1.508 & 0.22 \\
\hline No & $84(73)$ & $84(65)$ & & \\
\hline
\end{tabular}


Table 2. Responses to questions regarding the use of codeine-containing medicines in the preceding 3 months ${ }^{a}$

\begin{tabular}{|c|c|c|c|c|}
\hline Relevant questions/responses & $\begin{array}{l}\text { Pre-regulation } \\
{[n(\%)]}\end{array}$ & $\begin{array}{l}\text { Post-regulation } \\
{[n(\%)]}\end{array}$ & $\begin{array}{l}\chi^{2} / \text { Fisher's }^{\prime} \\
\text { exact test }^{\mathrm{b}}\end{array}$ & $p$-value \\
\hline \multicolumn{5}{|c|}{$\begin{array}{l}\text { When was the last time you took a codeine-containing } \\
\text { medicine? }\end{array}$} \\
\hline Less than a week before admission & $11(11)$ & $4(3.9)$ & \multirow[b]{2}{*}{$\mathrm{b}$} & \multirow[t]{2}{*}{0.05} \\
\hline More than a week before admission & $89(89)$ & $99(96.1)$ & & \\
\hline \multicolumn{5}{|c|}{ How often do you take codeine-containing medicines? } \\
\hline Rarely/sometimes & $66(66.7)$ & $76(82.6)$ & \multirow[t]{2}{*}{6.354} & \multirow[t]{2}{*}{0.01} \\
\hline Often/regularly & $33(33.3)$ & $16(17.4)$ & & \\
\hline \multicolumn{5}{|c|}{$\begin{array}{l}\text { When you take codeine-containing medicines are they } \\
\text { prescribed? }\end{array}$} \\
\hline Always/often & $13(13)$ & $20(19.4)$ & \multirow[t]{3}{*}{2.03} & \multirow[t]{3}{*}{0.362} \\
\hline Sometimes/rarely & $23(23)$ & $26(25.2)$ & & \\
\hline Never & $64(64)$ & $57(55.3)$ & & \\
\hline \multicolumn{5}{|c|}{$\begin{array}{l}\text { Are you aware that codeine-containing medicines could be } \\
\text { addictive? }\end{array}$} \\
\hline Yes & $69(66.3)$ & $73(61.9)$ & \multirow[t]{2}{*}{0.48} & \multirow[t]{2}{*}{0.48} \\
\hline No & $35(33.7)$ & $45(38.1)$ & & \\
\hline \multicolumn{5}{|c|}{$\begin{array}{l}\text { Do you consider yourself as being currently addicted to } \\
\text { codeine-containing medicines? }\end{array}$} \\
\hline Yes & $7(6.7)$ & $5(4.2)$ & \multirow[t]{2}{*}{0.672} & \multirow[t]{2}{*}{0.41} \\
\hline No & $97(93.3)$ & $113(95.8)$ & & \\
\hline \multicolumn{5}{|c|}{$\begin{array}{l}\text { Are you concerned about the frequency with which you } \\
\text { currently use codeine-containing medicines? }\end{array}$} \\
\hline Yes & $13(13.4)$ & $15(15.2)$ & \multirow[t]{2}{*}{0.122} & \multirow[t]{2}{*}{0.76} \\
\hline No & $84(86.6)$ & $84(84.8)$ & & \\
\hline \multicolumn{5}{|c|}{$\begin{array}{l}\text { Have others expressed concerns about the frequency with } \\
\text { which you currently use codeine-containing medicines? }\end{array}$} \\
\hline Yes & $15(15.5)$ & $5(4.8)$ & \multirow[t]{2}{*}{7.29} & \multirow[t]{2}{*}{0.03} \\
\hline No & $82(84.5)$ & $99(95.2)$ & & \\
\hline
\end{tabular}

${ }^{a}$ A number of patients did not respond to some of the questions. Furthermore, 17 (14.5\%) patients' pre-regulation and $23(18.25 \%)$ patients' post-regulation indicated that they had never used codeine-containing medicines.

${ }^{\mathrm{b}}$ Fisher's Exact Test was used for the comparison.

Table 3. Comparison of the reasons patients gave for taking codeine-containing medicines in the preceding 3 months

\begin{tabular}{|c|c|c|c|c|}
\hline $\begin{array}{l}\text { Reasons for taking } \\
\text { codeine-containing medication }\end{array}$ & $\begin{array}{l}\text { Pre-regulation } \\
{[n(\%)]}\end{array}$ & $\begin{array}{l}\text { Post-regulation } \\
{[n(\%)]}\end{array}$ & $\begin{array}{l}\chi^{2} / \text { Fisher's }^{\prime} \\
\text { exact test }^{\mathrm{a}}\end{array}$ & $p$-value \\
\hline Feel-good effect or to curb craving & $17(15.9)$ & $2(1.9)$ & a & 0.000 \\
\hline Migraine & $31(29)$ & $35(34.7)$ & 0.774 & 0.379 \\
\hline Aches and pains & $66(61.7)$ & $67(65)$ & 0.256 & 0.613 \\
\hline To treat infections/coughs and colds & $9(8.4)$ & $10(9.9)$ & 0.139 & 0.709 \\
\hline
\end{tabular}

\footnotetext{
${ }^{\text {a }}$ Fisher's Exact Test was used for the comparison.
}

medicines in the 3 months before admission (Table 2). There was also a reduction in the proportion of patients for whom others had expressed concerns about their frequency of use of such medications and again a decline in the proportion of patients who stated that they would use codeine-containing medicines for either a 'feel-good' effect or to curb cravings (Tables 2 and 3). Although codeine can be considered a relatively weak opioid analgesic, it is nevertheless addictive, and the misuse of medications containing codeine can cause significant morbidity in patients with codeine addiction (Dutch, 2008; Frei et al. 2010). In addition, codeine addictions are major social problems that impose a significant burden on society (Kreek et al. 2005). 
Our study indicates that there was no change in awareness among psychiatric patients about the addictive nature of codeine-containing medicines with the introduction of the new regulations on the supply of such medicines. Previous studies suggest that codeine addiction is uncommon in people who do not have existing vulnerability to addiction, including alcoholism (Stock, 1991). This is not supported by the findings of our study, which suggest that there may be no difference in the use of codeine-containing medicines by patients admitted for an addictive disorder with or without another mental health disorder and those admitted for a purely non-addictive disorder.

It has also been suggested that the low price and easy availability of codeine-containing medicines contributes significantly to their rapidly rising popularity as drugs of abuse (Mattoo et al. 1997). This observation appears to be consistent with findings from our study, which indicate that significantly more patients reported that they used codeine-containing medicines more frequently before the introduction of the regulation on the over-the-counter supply of such medicines compared to the period after the introduction of the regulation. In addition, there was a significant difference in the number of patients who reported that others had expressed concerns about the frequency with which the patients used codeine-containing medicines, with the former group being more likely to report that others had expressed such concerns about them compared with the later group. These observations may possibly reflect the relative ease of availability of codeine-containing medicines before the introduction of the regulation compared with the period afterwards. Although these comparisons are between two different groups of patients, the comparison is valid as there were no differences in the baseline demographic and clinical characteristics of the two groups.

Our study also indicates that significantly more patients in the former group compared with the later group used codeine-containing medicines either for a 'feel-good' effect or to curb craving. This suggests that significantly more patients abused codeine-containing medicines before the introduction of the new regulations compared with the period after that. In an Indian study of the socio-demographic and clinical profile of patients seeking treatment for abuse of codeinecontaining cough syrups, $96 \%$ of the patients reported a 'stimulant' effect of the cough syrup. This study also reported an opioid-like withdrawal in $92 \%$ of patients (Mattoo et al. 1997).

Our study has a number of limitations. First, although the questionnaire used for the survey was reviewed by a multi-disciplinary team, it lacks external validity, and thus our findings may not be generalisable to other jurisdictions. Second, the modest response rate of $65 \%$ and $68 \%$ pre and post implementation of the guidelines also affects the validity of our results. In particular, as we did not collect data on demographic and clinical variables of patients who did not consent to participate in the study, it would not be possible to generalise our results to this group of patients. Third, the results contain only self-reports of the use of codeine-containing medicines and may not be as reliable as collateral or biochemical reports. Furthermore, it is unclear to what extent any differences in abuse of codeine-containing substances reported between the two groups is due to a conscious effort by the later group to say that they did not abuse codeine-containing medicine after the introduction of regulatory guidelines. Fourth, the survey did not explore the supply of codeine-containing medicines over the internet, which could still occur with the introduction of the regulations. Fifth, we did not assess the types and quantities of codeine-containing medicines abused by patients, which is an important limitation. Finally, we did not explore the issue of whether or not the introduction of the new guidelines on codeinecontaining substances had any negative or unintended consequences such as the development of the black market, increase procurement of these substances over the internet or shift in abuse of other psychotropic substances. Notwithstanding these limitations, our study highlights significant reductions in self-reported abuse of non-prescribed codeine-containing medicines after the introduction of regulations limiting their supply in Ireland.

We conclude that tight regulation on the supply of non-prescribed codeine-containing medicines have the potential to reduce the abuse of such medicine among psychiatric patient populations.

\section{Declaration of Interest}

None.

\section{References}

Compton WM, Volkow ND (2006). Major increases in opioid analgesic abuse in the United States: concerns and strategies. Drug and Alcohol Dependence 81, 103-107.

Dutch MJ (2008). Nurofen Plus misuse: an emerging cause of perforated gastric ulcer. Medical Journal of Australia 188, 56-57.

Ernest D, Chia M, Corallo CE (2010). Profound hypokalaemia due to Nurofen Plus and Red Bull misuse. Critical Care and Resuscitation 12, 109-110.

Forman RF (2003). Availability of opioids on the internet. JAMA 290, 889

Frei MY, Nielsen S, Dobbin MD, Tobin CL (2010). Serious morbidity associated with misuse of over-the-counter codeine-ibuprofen analgesics: a series of 27 cases. Medical Journal of Australia 193, 294-296. 
Hou H, Yin S, Jia S, Hu S, Sun T, Chen Q, Fan R (2011). Decreased striatal dopamine transporters in codeinecontaining cough syrup abusers. Drug and Alcohol Dependence 118, 148-151.

Hastier P, Buckley MJM, Peten PE, Demuth N, Dumas R, Demarquay J-F, Caroli-Bosc F-X, Delmont J-P (2000). A new source of drug-induced acute pancreatitis: codeine. American Journal of Gastroenterology 95, 3295-3298.

Krausz M, Degkwitz P, Haasen C, Verthein U (1996). Opioid addiction and suicidality. Crisis 17, 175-181.

Kreek MJ, Bart G, Lilly C, LaForge KS, Nielsen DA (2005). Pharmacogenetics and human molecular genetics of opiate and cocaine addictions and their treatments. Pharmacologist Review 57, 1-26.

Lao YZ, Jiang ZY, Tong ZS, Pang ZT, Xu JX (2010). Clinical features and defense styles in patients with cough medicine abuse. Medical Journal of Chinese People's Health 22, 272-274.

Mattoo SK, Basu D, Sharma A, Balaji M, Malhotra A (1997). Abuse of codeine-containing cough syrups: a report from India. Addiction 92, 1783-1787.

Peters R Jr, Yacoubian GS Jr, Rhodes W, Forsythe KJ, Bowers KS, Eulian VM, Mangum CA, O'Neal JD, Martin Q, Essien EJ (2007). Beliefs and social norms about codeine and promethazine hydrochloride cough syrup
(CPHCS) use and addiction among multi-ethnic college students. Journal of Psychoactive Drugs 39, 277-282.

Pharmaceutical Society of Ireland (PSI) (2010). Non-prescription medicinal products containing codeine: guidance for pharmacists on safe supply to patients (http://www.thepsi.ie/Libraries/Consultations/Final_ Codeine_Guidelines.sflb.ashx). Accessed 20 June 2011.

Radat F, Irachabal S, Swendsen J, Henry P (2002). Analgesic abuse and psychiatric comorbidity in headache patients. Encephale 28(5 Pt 1), 466-471.

Shek DT, Lam CM (2006). Adolescent cough medicine abuse in Hong Kong: implications for the design of positive youth development programs in Hong Kong. International Journal of Adolescent Medicine and Health 18, 493-503.

Spillane JF (2004). Debating the Controlled Substances Act. Drug and Alcohol Dependence 76, 17-29.

Stock CJ (1991). Safe use of codeine in the recovering alcoholic or addict. Drug Intelligence \& Clinical Pharmacy 25, 49-53.

Thekiso T, Ahern S, Farren CK (2010). A study of 'over the counter' opiate abuse treatment. European Psychiatry 25, 1330.

Yang Y, Yuan QY (2008). Investigation and analysis on personalities of male-codeine phosphate addicts by MMPI. Chinese Journal of Drug Abuse Prevention and Treatment 14, 143-145. 